\title{
A descriptive study done to assess the quality of life among post myocardial infarction patients attending cardiac OPDs
}

\begin{abstract}
Introduction: Quality of life of post Myocardial infarction patient's condition refers to the satisfaction and dissatisfaction of life experienced by persons living with Myocardial Infarction. MI is one of the major causes of death among coronary artery diseases. Health related quality of life is an important measure of patient's recovery after an illness. It has suggested that different treatment may affect health related quality of life of patients with Myocardial Infarction. A descriptive study done to assess the quality of life among post myocardial infarction patients attending cardiac OPDs. The objective of the study was to assess the quality of life score among MI patients. To associate the quality of life score with selected socio demographic variables of post MI patients.
\end{abstract}

Method: Qualitative research approach was selected to assess the Quality of Life among post Myocardial Infarction patients. Total 60 cardiac patients were purposively selected to collect data using a checklist.

Results:

$$
\begin{array}{ll}
\text { i. } & 9(15 \%) \text { patients having good quality of life. } \\
\text { ii. } & 38(63.33 \%) \text { patients having average quality of life. } \\
\text { iii. } & 13(21.67 \%) \text { patients having poor quality of life. }
\end{array}
$$

Conclusion: According to gender, the maximum mean score 13.76 belonged to male gender followed by 11.6 in female gender. There was an association between quality of life and male gender. This study shows that gender is the only factor which is significant or affects the quality of life of Myocardial Infarction patients.
Volume 4 Issue 6 - 2017

\author{
Rupinder Kaur \\ Baba Farid University of Health Sciences, India
}

Correspondence: Rupinder Kaur, Army College of Nursing, Jalandhar Cantt, Punjab. University college of Nursing, Baba Farid University of Health Sciences, Faridkot, Punjab, India, Email dr.rupinder2507@gmail.com

Received: October 26, 2016 | Published: April 10, 2017

Keywords: quality of life, post MI patients, cardiac OPDs

\section{Introduction}

\section{Adaptability is not imitation means power of resistance and assimilation-Mahatma Gandhi}

Health related quality of life has been defined as a measure of the patient's perspective representing the functional effect of an illness and its consequent therapy upon a patient, as perceived by the patient. ${ }^{1}$ Health related quality of life is the value assigned to duration of life as modified by the impairments, functional status perceptions and social opportunities that are influenced by disease, injury, treatment or policy. As an outcome measure Health related quality of life (HRQL) more pragmatically represent what patients say about how they feel and function in their daily lives as a result of a disease or treatment and it generally include physical function and symptoms, psychological state and social interactions. ${ }^{2}$ Health-related quality of life [HRQL] has been defined by various authors; examples include HRQL as a measure of the patient's perspective representing the "functional effect of an illness and its consequent therapy upon a patient, as perceived by the patient" and that proposed by Patrick and colleagues as "the value assigned to duration of life as modified by the impairments, functional states, perceptions, and social opportunities that influenced by disease, injury, treatment, or policy". HRQL is now considered an important outcome measure in investigations of therapeutic interventions for patients with chronic conditions such as cancer and heart disease, in epidemiological studies and in patient care, representing a paradigm shift in the assessment of efficacy and effectiveness. $^{3}$

Coronary heart disease is the major cause of disability in many developed regions and by 2020 is forecast to be the major cause of disease burden world-wide. Patients who survive an acute coronary event may live for an extended period of time but often may be disabled, helping to drive the increased attention in HRQL outcomes in studies of coronary heart disease. As an outcome measure HRQL more pragmatically represents what patients say about how they feel and function in their daily lives as result of a disease or treatment and it generally includes, at a minimum, items about physical function and symptoms, psychological state, and social interaction. ${ }^{4}$ Acute Myocardial Infarction has negative consequences on the health related quality of life of the patients and that leads to lowering of their health related quality of life even several years after the acute myocardial infarction. During the first month after the acute myocardial infarction patients are very vulnerable physically, mentally and emotionally. ${ }^{5}$ It has been found that patients after MI reported the impairment in their daily lives, such as household work, physical activities and hobbies. Thus, physical and emotional disturbance of an Acute MI can be permanent and in many cases have damaging effects on 
the life styles of post MI patients thereby decreasing their overall quality of life. ${ }^{6}$ Quality of life related to post MI condition refers to the satisfaction or dissatisfaction of life experienced by persons living with MI as compared to the state before illness in physical, psychological, social and environment domains. Physical domains include nutrition, elimination, sleep, rest; psychological domains include feeling, learning, memory, sexual; environment domains include finance, freedom, physical security and safety, health and social care availability and participation in leisure activities. ${ }^{7}$

\section{Need for study}

Every day 20,000 new cases of heart diseases are detected in India. Approximately 135 million Indians are suffering from heart diseases at present. The incidence is still raising in spite of advancement in modern medicine and large number of expensive bypass or angioplasty procedures which sadly provide no lasting solution. According to WHO, expect committee estimates by the year of 2025, India will have highest number of heart diseases. ${ }^{8} \mathrm{MI}$ affects both physical and psycho-social aspects of patient's life. Maintaining and improving the QOL of patients is becoming increasingly important by health and social services professional as an important outcome or goal. There is a realization that ill-health cannot be discussed fully by measures of disease status but that the social, emotional and physical effects of the condition must also be encompassed. The area of research that has resulted from this recognition is known as health related Quality of life. ${ }^{8}$

MI has been reported to put a substantial burden on affected individuals by influencing physical as well as psychological, social, economical and practical aspects of life, where as only few studies on MI survivors has focused on the perception of these broad life domains in terms of multidimensional view of QOL. A study had found that patients after MI had reported the impairment in their daily life, such as household work, physical activities such as climbing stairs, sexual activities and hobbies, unable to perform the same level of work that they could do before the diagnosis of disease and low mood. Thus, physical and emotional disturbance of an acute MI can have permanent and in many cases, damaging effects on the life styles at post MI, thereby decreasing overall QOL for long run. ${ }^{5}$ After coming across the studies related to myocardial infarction and quality of life, interest aroused in the investigator to her investigate and find out the quality of life among post myocardial infarction patients and its association with socio- demographic variables respectively. So we have chosen this present study.

\section{Statement}

A descriptive study to assess the quality of life among post myocardial infarction patients attending cardiac OPD and IPD at selected hospitals in city Jalandhar, Punjab 2014

\section{Aim of study}

To assess the quality of life among post MI patients.

\section{Objectives of study}

To assess the quality of life score among post MI patient.To associate the quality of life score with selected socio-demographic variables.

\section{Assumptions}

Post myocardial infarction patients experience poor quality of life.

\section{Delimitations}

The study was delimited to post MI patients attending cardiac OPD at selected hospitals, district Jalandhar, Punjab.

\section{Inclusion criteria}

i. Patient who are available during study.

ii. Those who are willing to participate.

iii. Patients attending at cardiac OPD at selected hospitals city Jalandhar, Punjab.

\section{Exclusion criteria}

i. Those patients who are not willing to participate.

ii. Those who were not present at the time of study.

\section{Research approach}

Qualitative research approach was selected to assess the Quality of Life among post Myocardial Infarction patients.

\section{Research design}

The descriptive study was used to assess the Quality of Life among post Myocardial Infarction patients.

\section{Research setting}

The study was conducted in the month of June (2014) on the OPD and IPD patients in the S.G.L Charitable Hospital, Makkar Hospital, Apex Hospital, Shri Ram Cardiac centre, Oxford Hospital of District Jalandhar, Punjab.

\section{Population}

Patients who were suffering from myocardial Infarction.

\section{Target population}

Cardiac patients who were suffering from myocardial Infarction attending OPD and admitted in selected hospitals of Jalandhar, Punjab.

\section{Sample size}

Total 60 cardiac patients were selected from study in which 18 were taken from S.G.L Hospital, 13 were taken from Shri Ram cardiac centre, 12 were taken from Oxford Hospital, 12 were taken from Apex Hospital, 10 were taken from Makkar Hospital of Jalandhar, Punjab.

\section{Sampling technique}

The purposive sampling technique was used for selection of sample.

\section{Criteria for sample selection}

\section{Inclusion criteria}

i. Patients who were available at the time of study.

ii. Those who were willing to participate. 
iii. Patients attending cardiac OPD and IPD at selected hospitals of Jalandhar, Punjab.

\section{Exclusion criteria}

i. Those patients who were not willing to participate.

ii. Those who were not present at the time of study.

\section{Description of tool}

The following tools were used for assessing the Quality of Life among post Myocardial Infarction.

Part 1: It includes socio-demographic variables like age, sex, education, marital status, family, employment, income, occurrence of disease and other diseases.

Part 2: It consists of 25 questions of checklist to assess the quality of life among post Myocardial Infarction patients. Each items has score of 0 mark for 'Yes' answer and 1 mark for 'No' answer.

\section{Criterion measures}

There were 25 questions to assess the quality of life among post Myocardial Infarction patients. Each answer was in the rank order.

\section{Validity of tool}

The 10 experts from the field of nursing and medicine were given the tool for the validity. The experts are requested to give their valuable opinions and suggestions to develop better and relevant tool for the study. As per their guidance, changes have been made and items are modified.

\section{Reliability of tool}

The reliability of tool was obtained by Karl Parkson method. The reliability of tool was 0.85 .

\section{Ethical consideration}

i. Written permission was taken from the Principal of S.G.L Nursing College, Semi, Jalandhar. Ethical clearance was taken from the research committee of the S.G.L Nursing College, Semi, Jalandhar.

ii. Written permission was taken from the Administrator of the selected hospitals of the Jalandhar, Punjab.

iii. Written informed consent was taken from the each study sample. Confidentiality of each sample was maintained throughout the study.

\section{Data collection procedure}

Data collection was conducted during the month of June, 2014 from 60post Myocardial Infarction. Written permission was taken from the Administrator/ Director Nursing Superintendent of the selected hospitals of the Jalandhar, Punjab. A checklist was used for data collection by using purposive sampling techniques in selected hospitals. Purpose of the study was explained to patient. Confidentiality was maintained throughout the procedure of data collection.

\section{Plan of data analysis}

Data analysis and interpretation is the most important phase of the research process. It involves complications, editing, coding, classification and presentation of data. The analysis of the data was done by using descriptive mean, standard deviation, Karl Parkson method, chi square test was used to find out the association between Quality of Life among post Myocardial Infarction patients and their selected socio-demographic variable (Tables 1-3).

Table 4 depicted that according to age group, mean assessing score was highest 13.62 in the age group more than 70 years followed by score 12.57 in age group less than 50years, score 12.33 in age group $60-70$ years and score $12-15$ in age group 50-60 years. The mean assessing score was not significant because calculated value of test value 0.2733 was less than the tabulated value. So it was concluded that age had no impact on quality of life among post myocardial infarction patients. According to Gender, mean assessing score 13.76 was highest in the male group followed by 11.6 in the female group. The mean assessing score was significant because calculated value of test value 2.1637 was more than male tabulated value. So it was concluded that male gender had impact on quality of life among post myocardial infarction patients.

Table I Criterion measures

\begin{tabular}{ll} 
Quality of life & Scoring \\
\hline Poor & $0-8$ \\
Average & $9-16$ \\
Good & $17-25$
\end{tabular}

Table 2 Frequency and percentage distribution of socio demographic variables

\begin{tabular}{|c|c|c|c|}
\hline S.No. & Socio demographic variables & $\mathbf{n}$ & $\%$ \\
\hline $\mathbf{I}$ & Age & & \\
\hline a) & Less than $50 y e a r s$ & 14 & 23.33 \\
\hline b) & $50-60$ years & 20 & 33.33 \\
\hline c) & $60-70$ years & 18 & 30 \\
\hline d) & More than $70 y e a r s$ & 8 & 13.34 \\
\hline 2 & Gender & & \\
\hline a) & Male & 25 & 41.67 \\
\hline b) & Female & 35 & 58.33 \\
\hline 3 & Education & & \\
\hline a) & Primary & 18 & 30 \\
\hline b) & Secondary & 12 & 20 \\
\hline c) & Graduate & 9 & 15 \\
\hline d) & Post-graduate & 21 & 35 \\
\hline 4 & Marital Status & & \\
\hline a) & Married & 60 & 100 \\
\hline b) & Unmarried & 0 & 0 \\
\hline c) & Other & 0 & 0 \\
\hline 5 & Type of Family & & \\
\hline a) & Nuclear & 34 & 56.67 \\
\hline b) & Joint & 26 & 43.33 \\
\hline
\end{tabular}


Table Continued

\begin{tabular}{llll}
\hline S.No. & Socio demographic variables & n & $\%$ \\
\hline 6. & Occupation & & \\
a) & Private & 18 & 30 \\
b) & Government & 2 & 3.33 \\
c) & Retired & 6 & 10 \\
d) & Labourer & 4 & 6.67 \\
e) & Unemployed & 30 & 50 \\
7 & Monthly Family Income & & \\
a) & Less than 10,000 & 19 & 31.67 \\
b) & I0,000-20,000 & 19 & 31.67 \\
c) & 20,000-40,000 & 11 & 18.33 \\
d) & More than 40,000 & 11 & 18.33 \\
8 & Occurrence of Myocardial Infarction & \\
a) & Less than lyear & 22 & 36.67 \\
b) & I-4year & 13 & 21.66 \\
c) & $4-6$ year & 7 & 11.66 \\
d) & More than 6year & 18 & 30 \\
a) & Associated Diseases & 26 & 40 \\
b) & CAD & 20 & 33.33 \\
\hline & Hypertension & 0 \\
\hline
\end{tabular}

Table 3 Percentage distribution to assess the quality of life among post myocardial infarction patients

\begin{tabular}{llll}
\hline Level (Quality of life) & Score & N & $\%$ \\
\hline Poor & $0-8$ & 13 & 21.67 \\
Average & $9-16$ & 38 & 63.33 \\
Good & $17-25$ & 9 & 15
\end{tabular}

Maximum score $=25$

Minimum score $=0$
Table 4 Associate between mean assessing score regarding quality of life among post myocardial infarction patients according to selected sociodemographic variables

\begin{tabular}{|c|c|c|c|c|c|c|}
\hline S.No & $\begin{array}{l}\text { Socio } \\
\text { demographic } \\
\text { variables }\end{array}$ & $\mathbf{n}$ & Mean & SD & Test value & Df \\
\hline 1 & Age & & & & & \\
\hline a. & $\begin{array}{l}\text { Less than } \\
50 \text { years }\end{array}$ & 14 & 12.57 & 4.71 & 0.2733 & 3,56 \\
\hline b. & 50-60years & 20 & 12.15 & 3.92 & & \\
\hline c. & 60-70years & 18 & 12.33 & 3.1 & & \\
\hline d. & $\begin{array}{l}\text { More than } \\
\text { 70years }\end{array}$ & 8 & 13.62 & 4.85 & & \\
\hline 2 & Gender & & & & & \\
\hline a. & Male & 25 & 13.76 & 3.87 & $t=2.1637$ & 58 \\
\hline b. & Female & 35 & 11.6 & 3.76 & & \\
\hline 3 & Education & & & & & \\
\hline a. & Primary & 18 & 10.88 & 4.35 & 1.4909 & 3,56 \\
\hline b. & Secondary & 12 & 13 & 2.52 & & \\
\hline c. & Graduate & 9 & 13.22 & 2.27 & & \\
\hline d. & Post graduate & 21 & 13.28 & 4.52 & & \\
\hline 4 & Marital Status & & & & & \\
\hline a. & Married & 60 & 12.5 & 3.92 & & \\
\hline b. & Unmarried & 0 & & & & \\
\hline c. & Others & 0 & & & & \\
\hline 5 & Type of Family & & & & & \\
\hline a. & Nuclear & 34 & 12.73 & 3.58 & 0.5271 & 58 \\
\hline b. & Joint & 26 & 12.19 & 4.39 & & \\
\hline 6 & Occupation & & & & & \\
\hline a. & Private & 18 & 13.27 & 4.16 & 1.6096 & 4,95 \\
\hline b. & Government & 2 & 11 & 5.65 & & \\
\hline c. & Retired & 6 & 15.83 & 1.47 & & \\
\hline d. & Labourer & 4 & 12 & 3.16 & & \\
\hline e. & unemployed & 30 & 11.53 & 3.83 & & \\
\hline 7 & Monthly Family I & come & & & & \\
\hline a. & less than 10,000 & 19 & 13.31 & 3.94 & 0.5344 & 3,56 \\
\hline b. & $10,000-20,000$ & 19 & 12.42 & 4.41 & & \\
\hline c. & $20,000-40,000$ & 11 & 12.27 & 2.83 & & \\
\hline d. & $\begin{array}{l}\text { More than } \\
40,000\end{array}$ & 11 & 11.45 & 4.18 & & \\
\hline 8 & Occurence of Dis & ase & & & & \\
\hline a. & Less than 1year & 22 & 13.13 & 4.24 & 0.4441 & 3,56 \\
\hline b. & 1-4years & 13 & 12.3 & 3.72 & & \\
\hline c. & 4-6years & 7 & 12.85 & 3.84 & & \\
\hline d. & $\begin{array}{l}\text { More than } \\
\text { Gyears }\end{array}$ & 18 & 11.72 & 3.87 & & \\
\hline
\end{tabular}


Table Continued

\begin{tabular}{lllllll}
\hline S.No & $\begin{array}{l}\text { Socio } \\
\text { demographic } \\
\text { variables }\end{array}$ & $\mathbf{n}$ & Mean & SD & Test value & Df \\
\hline $\mathbf{9}$ & Associated Diseases & & & & \\
a. & CAD & 24 & 13 & 3.4 & 0.6742 & 2,57 \\
b. & Hypertension & 20 & 11.55 & 4.27 & & \\
c. & Renal disease & 0 & 0 & 0 & & \\
d. & Diabetes & 16 & 12.93 & 4.25 & & \\
\hline
\end{tabular}

\section{Discussion}

The first objective was to assess quality of life among post myocardial infarction patients. The findings of study revealed that 13patients (21.67\%) have poor quality of life, 38patients $(63.33 \%)$ have average quality of life and only 9 patients $(15 \%)$ have good quality of life. The similar study was conducted by A.U. Saleh et al (2010). They were taken 100 patients in their study. The findings of the study showed: Mean age 53.99years. $81 \%$ were males and $19 \%$ were females. Mean age of females 56.0years and males 53.4years. $49 \%$ patients belong to age group $51-70$ years, $44 \%$ to $31-50$ years, $7 \%$ to $71-90$ age groups. The Majority $(51.85 \%)$ of male patients were from 51-70years age group and the majority of female patients $(52.63 \%)$ from $31-50 y e a r s$ age group.

\section{Objective-2}

The second objective was to associate the quality of life score variables of post myocardial infarction. The present study showed that there was not significant association of mean score with Age, Education, Marital status, Type of family, Monthly income, associated diseases. Mostly the quality of life of male patients is affected by myocardial infarction. According to test value $2.1637 \%$ quality of male gender is affected The similar study was conducted in 2008, Laszlo J. Baltinoec, William and wilkin study of prognosis for 1739 survivors of myocardial infarction, we reported an elevated risk of death among men with low levels of education. As per Gender, The depicted that mean assessing score 13.76 was highest in the male group followed by 11.6 in female group. The mean assessing score was significant because calculated value of test value 2.1637 was more than male tabulated value. So it was concluded that male gender had impact on quality of life among post myocardial infarction patients. Similar study was conducted in 2007 by Nagaraju B, Padmavathi GV et al. In this study, the data was analyzed using descriptive and inferential statistics. Majority of the patients, $48.6 \%$, had moderate quality of life. Male patients had better quality of life comparing to female patients. A statistically significant association was found between gender and quality of life of myocardial infarction outpatients Interpretation and conclusion: Findings of the study showed that majority of patients $48-6 \%$ had moderate quality of life among which majority of female patients had poor quality of life. This indicates that the incidence of Myocardial infarction is on the rise and it affects the quality of life of the Indian population. Further attention has to be given to improve the quality of life of post Myocardial Infarction clients.

\section{Conclusion}

From the findings of the study regarding quality of life among post myocardial infarction patients, following conclusions are drawn:

i. In the age group, the mean score 13.62 was maximum in age group more than 70years followed by 12.57 in the age group less than 50 years, 12.33 in 60-70years and 12.15 in 50-60years.

ii. According to gender, the maximum mean score 13.76 belonged to male gender followed by 11.6 in female gender. There was an association between quality of life and male gender. According to test value $2.1637 \%$ quality of life of male gender is affected more in comparison to females.

iii. With regard to education, the highest mean score 21 was among the post graduate patients, 18 in the primary level of education, 12 in secondary level of education and 9 in the graduate patients.

According to marital status, the mean score was highest 12.5 in married patients

i. With reference to type of family, the maximum mean score 12.73 belongs to nuclear family followed by 12.19 in the joint family.

ii. As per occupation, the maximum mean score 15.83 was in the retired patients, 13.27 was in private employs, 11.53 in the unemployed patients, 12 in the labourer and 11 in the government employees.

iii. According to monthly family income, the highest mean score 13.31 was in the patients having less than 10,000 Rs monthly income followed by 12.42 among patients having 10,000- 20,000 Rs, 12.27 in the 20,000-40,000 Rs and 11.45 in the patients having more than 40,000 Rs monthly income.

iv. With regard to occurrence of diseases, in less than 1 year the mean assessing score was $13.13,12.85$ in the $4-6$ year,12.3 in the 1-4 year and 11.72 in the more than 6 years.

v. As per associated diseases, the highest mean score 13 was in the coronary artery disease patients followed by 12.93 was in the diabetic patients, 11.55 in the hypertensive patients.

\section{Recommendations}

On the basis of findings of the study following recommendations are offered for the further research:

i. An Exploratory study can be conducted to find factors affecting quality of life among Post Myocardial Infarction patients.

ii. This study can provide guidelines to the future researchers, who are interested in assessing quality of life of post Myocardial Infarction patients.

\section{Acknowledgements}

None.

\section{Conflict of interest}

The author declares no conflict of interest.

\section{References}

1. Moller JT, Cluitmans P, Rasmussen LS, et al. Long term post operative cognitive dysfunction in elderly: ISPOCD 1 study. Lancet. 1998;351(9106):857-861.

2. Newman MF, Croughwell ND, Blumenthal JA, et al. Predictors of cognitive decline after cardiac operation. Ann Thorac Surg. 19995;59(5):1326-1330. 
3. Spilker B. Quality of life studies: definitions and conceptual issues (page 16). Quality of life and pharmacoeconomics in clinical trials. 2nd ed. USA: Lippincott-Raven; 1996. p. 1-9.

4. Elinkton J. Medicine and quality of life. Annals Int med. 1996;64(3):711714.

5. Brown N, Melville M, Gray D, et al. Quality of life four years after acute myocardial infarction: short for 36 scores compared with normal population. Heart. 1999;81(4):352-358.
6. Goble A, Worcester M. Best practice guidelines for cardiac rehabilitation and secondary prevention. Department of human services: Victoria, Australia; 1999. p. 1-27.

7. WHO. Measuring quality of life. Nsg Journal of India. 1997;4(2):1-15.

8. Westwin L, Carlsson R, Erhardt L, et al. Differences in quality of life in men and women with ischemic heart disease. A prospect controlled study. Scand Cardiovascular J. 1999;33(3):160-165. 